\title{
Correlative Analysis between Expression of Estrogen Receptor, Progesterone Receptor, and HER2 Receptor and Clinicopathologic Features in Endometrial Cancer
}

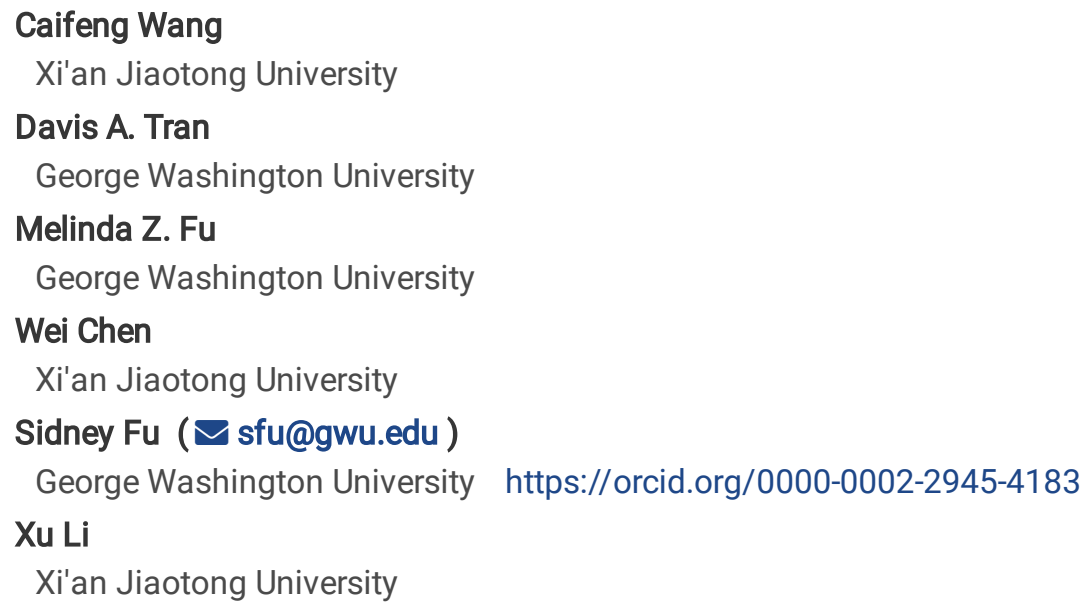

Research article

Keywords:

Posted Date: October 11th, 2019

DOI: https://doi.org/10.21203/rs.2.15912/v1

License: () (i) This work is licensed under a Creative Commons Attribution 4.0 International License. Read Full License 


\section{Abstract}

Background: Endometrial cancer $(E C)$ is a major gynecologic adenocarcinoma that arises from the endometrium. While the incidence of EC is on the rise worldwide, survivorship and clinical advancement have considerably lagged behind compared to other cancers. Given the sensitive nature of the endometrium and its high expression of hormone receptors, hormonal therapy has become a favorable alternative treatment compared to highly toxic chemotherapeutics and radiation therapy.

Methods: Clinical samples from patients diagnosed with EC were obtained. ER and PR staining was performed according to the S-P kit, and HER2 staining was carried out according to the UltrasensitiveTM S-P immunohistochemistry kit protocol. Chi-square analysis was conducted using the SPSS. P-values of less than 0.05 were taken as an a priori value for statistical significance.

Results: Immunohistochemical (IHC) analysis showed the overall positive expression rates of ER, PR, and HER2 to be $59.8 \%, 75.0 \%$, and $71.1 \%$, respectively. Significant co-expression was found among all three receptors, suggesting a cooperative, synergistic effect. More importantly, we found that ER expression was correlated with FIGO staging and cervical invasion, whereas PR expression was associated with histologic type. No clinicopathologic features were correlated with HER2 expression, but HER2 positivity was inversely associated with the degree of HER2 overexpression.

Conclusions: These results suggest that EC is a heterogeneous disease that may not conform to traditional, prototypically defined subtypes. The status of ER, PR, and HER2 receptors may have the potential to serve as prognostic indicators for EC, but further analysis is needed to ascertain their prognostic significance.

\section{Background}

Endometrial cancer (EC) is a major gynecologic adenocarcinoma that arises from uninterrupted endometrial proliferation due to unopposed estrogen stimulation; predominantly in women of postmenopausal age [1-3]. Worldwide, EC is the sixth most commonly diagnosed cancer in females, with the highest prevalence found among developed nations in North America as well as Northern and Eastern Europe [1, 4]. In the United States and Canada, EC stands as the most common gynecologic cancer, whereas in China, EC is second only to cervical cancer [American Cancer Society 2019;4, 5, 6]. The incidence rate of EC is on the rise in 26 populations globally, with the greatest increase in Asia and Africa, largely due to their rapid socioeconomic transition [1].

In the United States, EC is one of few malignancies with increasing incidence and mortality. Between 1999-2016, EC incidence rose $0.7 \%$ per year, while mortality had a greater increase of $1.1 \%$ per year [7]. Paradoxically, the survivorship for EC has worsened in the last four decades. The five-year survival rate between 1975 to 2014 has fallen from $86.9 \%$ to $82.7 \%$ (p<.05) and as of 2019, has decreased to $81.2 \%$ [American Cancer Society 20195,8 ]. In China, there has been a significant rise in EC incidence [9]. While data at the national level is not available, the most recently cited five-year survival rate for one registry is $55.1 \%$, which is comparatively lower to the age-adjusted survival rate of $67 \%$ among developing nations $[6,9,10]$.

Traditionally, EC lesions have been classified into two distinctive pathogenetic subtypes that differ in histological and molecular characteristics as defined by Bokhman [11]. Type I consists of estrogen-dependent and low-grade lesions of endometrioid morphology with high mutations in PTEN $[2,4,12]$. Type I tumors are more common (80\% of cases) and are considered less aggressive, often found in early stage according to the Federation of Gynecology and Obstetrics (FIGO stage I-II), with high positivity for ER and PR as indicators of favorable prognosis [13]. Type II is rarer and contains high-grade lesions of serous or clear-cell histology with frequent mutations in TP53 and high expression and/or amplification of HER2 [2, 14]. Prognosis with type II tumors is generally poor with a higher chance for recurrence, as there is a predilection for deep myometrial invasion with more advanced stages (FIGO stage III-IV). Five-year overall survival for high-grade lesions amass only to $17 \%$, with limited options beyond chemotherapy [15]. While such classification on the basis of clinical, histological, and molecular features provides a powerful framework to derive potential prognostic markers for EC, the increasing heterogeneity within and overlap between type I and type II cancers is gaining more recognition [4]. Thus, caution must be taken when determining the prognostic significance of hormone receptor status based solely on the dichotomous Bokhman classification.

Aside from clinical and pathological characteristics, endocrine markers in the form of ER, PR, and HER2 are particularly attractive as prognostic markers for EC given their direct involvement in the normal regulation and maintenance of endometrial health [16]. In the regular progression of the menstrual cycle, the lining of the uterus is subject to a pair of steroid hormones, estrogen and 
progesterone, that each exerts an opposing effect on the endometrial glandular epithelium $[13,17,18]$. In particular, estrogen has a mitogenic effect that drives the proliferation of the endometrial epithelium via ER. Left unopposed, estrogen can lead to the rapid onset of endometrial hyperplasia and consequently, the development of EC. Progesterone, however, acts as an antagonist to estrogen by downregulating ER expression, inhibiting active cell division, and promoting cell differentiation through PR [18, 19].

As the endometrium expresses both ER and PR, the lining of the uterus is highly sensitive to hormone activity [18]. Therefore, any shift to the endocrine balance in favor of high estrogen level will ultimately stimulate oncogenesis. Such overexposure to estrogen arises in the majority of type I tumors, which also becomes a high risk factor among women undergoing estrogen-only hormonal therapy, using tamoxifen as adjunct therapy for breast cancer, facing obesity as adipose tissue releases estrone, which is converted into estradiol in the uterus, or suffering from PCOS (polycystic ovary syndrome) [20, 21].

HER2, a well characterized oncogene in the pathogenesis of breast cancer, has also been implicated as a potential biomarker for type II tumors [22]. In brief, overexpression of HER2 results in sustained cell proliferation via constitutive activation of the kinase domain in a ligand-independent manner [14]. While HER2 expression is mostly associated with a poor prognosis in type II lesions, recent studies suggest $1-47 \%$ of HER2 overexpression is also found in advanced and recurrent type I endometrioid carcinomas [14]. Given the need for receptors for hormones to successfully exert their downstream effects on the endometrium, hormone receptor status may therefore be a valuable prognostic marker for EC development and progression.

Staged surgery is currently the only primary treatment for EC, followed by adjuvant chemotherapy or radiation therapy [2, 23]. As EC patients are generally of older age and are more likely to have comorbidities, the aversive side effects from chemotherapy are unable to justify the low response rate (less than $20 \%$ ) $[15,24]$. Furthermore, $14 \%$ of all EC cases are found in women of child-bearing age $[18,25]$. As such, hormone therapy is an attractive treatment not only for its lower toxicity profile, but also for its use in preserving fertility among younger EC patients.

Even though there is a number of studies on the potential use of hormone receptor status to refine outcome predictions for EC, the prognostic significance of hormone receptor profiles in EC remains unclear [26]. Even fewer studies are available on receptor status in Chinese population. In an attempt to characterize the prognostic value of hormone receptors on a global level, Y Zhang, D Zhao, C Gong, F Zhang, J He, W Zhang, Y Zhao and J Sun [13] conducted a systematic review and meta-analysis for the expression rate of ER, PR, and HER2 in EC, with 48, 38, and 16 studies, respectively. Of those selected for inclusion, only 3 studies pertained specifically to Chinese population in regard to ER and PR status. Moreover, studies involving HER2 expression in Chinese women were not included. Therefore, the present study seeks to investigate the hormone receptor status of ER, PR, and HER2, both independently and collectively, in a cohort of Chinese women. Receptor expression rates are also analyzed for associations to clinicopathologic characteristics in an effort to determine the prognostic value of receptor status in EC.

\section{Methods}

\section{Study Participants}

In total, this study consisted of 204 women of Chinese descent that were residents of or within the neighboring regions of Shaanxi province between June 2000 and February 2007. Of the 204 participants, 89 were diagnosed with EC while 115 served as controls, presenting with no current or history of cancer and systemic diseases. The women varied in age, from 30-80 years with a median age of 60 years. Participants took a self-administered study questionnaire requesting relevant medical and social history.

\section{Sample Collection and Classification}

Clinical samples from patients diagnosed with EC were obtained between June 2000 and February 2007, after radical surgery or total hysterectomy in the Department of Gynecology and Obstetrics at the First Affiliated Hospital of Xi'an Jiaotong University, in Xijing Hospital of the Fourth Military Medical University, and at the Shaanxi Provincial People's Hospital and Xi'an Fourth Hospital within Shaanxi province. The patients varied in age, between 30 to 80 years, with a median of 60 years. The samples were matched with a control population with an age range of 31 to 79 years, with a median age of 46 years. The study protocols were approved by our institution's ethics committee and all participants were consented. 
EC patient samples were then subject to analysis and classification based on histologic subtype (type I or type II), surgical staging (IIV) according to the Federation of Gynecology and Obstetrics (FIGO) 2009 criteria, histologic grade (G1-G3), and invasive status to the myometrium and cervix.

\section{Immunohistochemistry assay}

ER and PR staining was performed according to the S-P kit (Beijing Zhongshan Jinqiao Biotechnology Co., Ltd.), and HER2 staining was carried out according to the UltrasensitiveTM S-P immunohistochemistry kit protocol (Maixin Biotechnology Development Co., Ltd.). The S-P immunohistochemistry kit uses a biotin-labeled secondary antibody and a streptavidin-linked peroxidase, and the substrate pigment mixture to determine antigens in the nucleus. The PBS solution was used as a negative control, and the known positives provided by the company were used as positive controls.

The overall expression levels of ER $(n=82)$, PR $(n=80)$ and HER2 $(n=76)$ were detected in formalin-fixed and paraffin embedded (FFPE) tissue by immunohistochemistry (IHC) assay in 4-mm thick sections. In brief, samples were deparaffinized with xylene and rehydrated with $0.3 \%$ hydrogen peroxide $\left(\mathrm{H}_{2} \mathrm{O}_{2}\right)$ solution. After immersion in a $10^{-3} \mathrm{M}$ sodium citrate buffer, the slides were pressurized for $1 \mathrm{~h}$, after which they were cooled and washed with phosphate buffered saline (PBS). Tissues were then incubated in primary antibodies overnight at $4 \mathrm{C}$, retrieved, and washed with PBS. Following incubation in biotinylated anti-mouse secondary antibodies and streptavidin for 30 mins at room temperature, the samples were stained with alkaline phosphatase enzyme conjugates. Comparative staining was conducted with hematoxylin. Two pathologists with no prior information concerning scored clinical variables interpreted all immunohistochemical staining results. A cut-off value of $10 \%$ for positively stained cells per ten high-power fields was used in the classification of the ER, PR and HER2 protein expression.

\section{Statistical Analysis}

Chi-square analysis was conducted using the SPSS. P-values of less than 0.05 were taken as an a priori value for statistical significance.

\section{Results}

\section{ER Expression \& Association with Clinicopathologic Features}

The expression rate for ER positivity was 59.8\% (Table 1). ER proteins were found primarily expressed in the nucleus (Figure 1). ER expression showed statistically significant correlation with FIGO staging, histologic grade, and cervical invasion $(p<0.05)($ Table 2). In particular, there was a significant association between ER positivity and FIGO stage I (69.1\%). A significant difference in ER expression among various FIGO stages was observed. ER expression further showed a significant association with histologic grade G1 (74.2\%) and cervical invasion (36.8\%). There was no significant association between ER status with either histologic type or myometrial invasion.

\section{PR Expression with Clinicopathologic Features}

The expression rate for PR positivity was $75.0 \%$ (Table 1). PR protein was primarily expressed in the cell nucleus (Figure 2). PR expression was correlated to the difference in histologic type (77.6\% type I vs. $25.0 \%$ type II) and FIGO stage I (81.1\%) with statistical significance (Table 2). PR expression showed no significant correlation in either histologic gradation or invasion status of the myometrium or cervix.

\section{HER2 Expression in Histologic Types of EC and Association with Clinicopathologic Features}


The positive expression rate for HER2 was $71.1 \%$, with a strong overexpression rate $(3+\mathrm{HHC})$ of $2.8 \%$ in endometrioid endometrial carcinoma (EEC) (Table 1 \& Table 3). HER2 protein was expressed in both cytoplasm and membrane (Figure 3). HER2 expression showed no significant correlation to any clinicopathologic parameter or histologic classification. However, when analyzed in endometrioid EC, there was a significant negative association between HER2 positivity and the degree of HER2 expression $(p<0.05)$ (Table 3). HER2 status was also investigated based on EC's distinct variants, which showed positive HER2 expression in $72.1 \%$ cases of endometrioid endometrial carcinoma (EEC), 25.5\% non-endometrioid endometrial carcinoma (NEC), 50\% clear cell carcinoma (CCC), $0 \%$ uterine papillary serous carcinoma (UPSC), and 0\% squamous carcinoma (SC) (Table 3).

\section{Co-expression of ER, PR, \& HER2}

The co-expression of each pair of the three hormone receptors was analyzed. Each pair showed a positive and significant correlation $(p<0.01)$. Specifically, out of 54 HER2-postive cases, $70.4 \%$ was found to have positive co-expression of HER2 and ER $(p<0.01)$ (Table 4a). In addition, in 55 HER2-positve cases, 83.6\% was found to have co-expression between HER2 and PR $(\mathrm{p}=0.01)($ Table 4b). Lastly, in 45 ER-positive cases, $95.6 \%$ was found to have co-expression between ER and PR $(p=0.01)($ Table $4 c)$.

\section{Discussion}

\section{Independent ER \& PR Receptor Status in EC}

Given the endometrium's high sensitivity to steroid hormones and the significant impact hormones have in modulating endometrial growth, molecular tumor classification based on receptor status is suspected to play an important prognostic role in the management and treatment of EC. The presence of steroid receptors ER and PR, in particular, have been considered to be associated with favorable outcomes in the majority of type I tumors $[2,13,17,19,27]$; however, its prognostic significance is not universally accepted and remains unclear (Jeon et al. 2006). In this study, both ER and PR protein were expressed in the cell nucleus (Figure 1 \& 2).. The positive expression rates for ER and PR were $59.8 \%$ and $75.0 \%$, respectively (Table 1). Such figures are in agreement with previous studies [23, 26-29]. Among them, the most recent figures by D Tomica, S Ramic, D Danolic, L Susnjar, M Peric-Balja and M Puljiz [28] reported a positive rate of $65.2 \%$ for ER expression and $59.4 \%$ for PR expression in a Caucasian population. Interestingly, while our data on ER and PR receptor status resonates with those found in a Caucasian population, our positive rates are lower in comparison to those reported in a Chinese cohort by F Shen, Y Gao, J Ding and Q Chen [17], which showed an overall rate of $85 \%$ for both ER and PR expression. Such disparity may be the result of the sequential loss of receptors in disease progression [26], as patients were neither stratified by the year of diagnosis, nor was the duration of EC analyzed in either study.

\section{The Independent Association of ER \& PR Receptor Status with Clinicopathologic Features}

Bokhman classification, FIGO surgical staging, histologic grade, and invasion status are well accepted prognostic factors that show a significant association with patient survival in EC [28,30]. Hormone receptor status is also correlated with the aforementioned clinicopathologic traits. Specifically, the loss of ER and PR status is associated with EC lesions that are designated as type II, of higher tumor grade, and are more prone to deep myometrial invasion $[2,3,17,28,29,31]$. In this study, the statistically significant difference in FIGO staging by immunohistochemistry $(\mathrm{IHC})$ further lends support to the notion that a decrease in ER expression is correlated to more advanced stages of EC $(\mathrm{p}<0.05)$ (Table 2). A similar inverse trend is observed with PR status and FIGO stages. However, with the exception of stage I and PR expression, the difference among stages are statistically insignificant with PR status. This suggests ER expression is a better indicator of FIGO staging compared to PR status, at least among Chinese women found in this study.

While ER expression was not correlated with histologic type, PR receptor status did exhibit a significant association in the difference between histologic types I vs. type II (Table 2). This suggests that PR status is a more reliable predictor of patient outcome when compared to ER status when histologic type is analyzed in isolation. However, the limitations of a smaller sample size of cases for type II tumors, advanced staging, and lesions of higher grade must also be recognized. 
F Shen, Y Gao, J Ding and Q Chen [17] [17][17]noted that while ER and PR status were higher among type I patients in their Chinese cohort as expected, the majority of type II patients also contained notable levels of ER and PR expression. However, we found PR expression in only $25 \%$ of type II patients compared to $77.6 \%$ of type I patients (Table 2). The differences observed may therefore suggest EC is a heterogeneous disease that may have attributes outside of those historically defined by the dichotomous Bokhman classification system $[12,22]$. It is noteworthy to recognize that in light of substantial heterogeneity within and between type I and type II cancers, Bokhman's type I and type II are not part of the formal FIGO staging or risk stratification processes, and therefore has no clinical utility as discussed [4]. Not all endometrioid lesions act in the same prototypical type I fashion and vice versa [2]. In fact, a number of type I lesions are of high grade and appear to be as aggressive as traditionally characterized type II lesions [2]. More recently, the Cancer Genome Atlas (TCGA) focused on molecular subgroups of EC and identified how endometrioid lesions, classically designated as type I, exhibited heterogeneity within the group as cases varied in mutation load, grade, and prognosis [4, 12].

Although the difference in histologic grade and invasion status may be statistically insignificant, a cogent negative trending association is apparent between the loss of both ER and PR receptors in higher grade tumors, myometrial invasion, and cervical invasion (Table 2). Furthermore, ER expression levels in histologic grade G1 and cases in which cervical invasion had occurred were both of statistical significance (Table 2). Taken together, our data is in concordance with the general association between independently high ER and PR status with a favorable prognosis of EC [13].

\section{HER2 Receptor Status in EC}

In a similar fashion to ER and PR, HER2 has been investigated for its prognostic value in endometrial cancer, but its prognostic significance also remains controversial $[14,22]$. Contrary to ER and PR expression found predominantly in the cell nucleus, HER2 protein was found in both the cell cytoplasm and membrane (Figure 3). Furthermore, we identified HER2 expression in $71.1 \%$ of all EC cases, which is comparable to the reported positive rate of $71.1 \%$ by D-P Wang, I Konishi, M Koshiyama, M Mandai, Y Nabu, Y Ishikawa, T Mori and S Fuji [32] in a Japanese cohort as opposed to 7.14\% by S Waqar, SA Khan, T Sarfraz and S Waqar [3] among Pakistani women (Table 1). However, much attention concerning HER2 status has been focused on its association with more aggressive type II lesions, particularly in uterine papillary serous carcinoma (UPSC) [2, 14, 19, 22]. In the literature, expression of HER2 varied over a range from 14 to $80 \%$ [2, 14, 33-35]. Interestingly, our IHC analysis did not detect HER2 expression in UPSC (Table 3). Rather, endometrioid endometrial carcinoma (EEC) contained the highest level of HER2 expression at $72.1 \%$, with a strong protein overexpression rate $(3+\mathrm{IHC}$ ) of $2.9 \%$ (Table 3). While IHC data on HER2 status in UPSC is inconsistent with the majority of prior reports, HER2 positivity in EEC has been documented to appear within a range of $1 \%$ to $47 \%$ in advanced-stage type I lesions [14] in spite of some disagreement [33]. It is also important to note that the lack of HER2 detection may be attributable to the small number of UPSC cases $(n=1)$ compared to EEC $(n=68)$. Furthermore, there was a statistically significant difference in the inverse relationship between decreasing HER2 positivity rates and the degree of HER2 expression or IHC score $(\mathrm{p}<0.05)($ Table 3$)$. The positive rates for non-endometrioid endometrial carcinoma (NEC), clear cell carcinoma (CCC), and squamous carcinoma (SC) were $25.0 \%, 50 \%$, and $0 \%$, respectively. Nevertheless, such positivity for HER2 in EEC (72.1\%) further underscores both the heterogeneity and complexity of EC.

\section{Association of HER2 Receptor Status with Clinicopathologic Features}

While our data shows HER2 expression did not significantly correlate with any histologic subtype or clinicopathologic characteristic, it is still noteworthy to analyze the trends between HER2 status and clinicopathologic features (Table 2). Y Zhang, D Zhao, C Gong, F Zhang, J He, W Zhang, Y Zhao and J Sun [13] suggested that high HER2 positivity is associated with an unfavorable prognosis, whereas high ER and PR positive rates are good predictors of patient survival. Surprisingly, HER2 was found to exhibit low expression in both high-grade tumors and in positive cases of cervical involvement, a trend similarly seen in ER and PR receptor status (Table 2). Additionally, HER2 status was more associated with type I tumors than type II (72.1\% vs. 25.0\%). Yet, HER2 maintained high positivity for advanced FIGO stages and myometrial involvement, albeit statistically insignificant. Such results suggest the importance of adopting a comprehensive approach to guide therapeutic and clinical decisions as opposed to relying on any one clinicopathologic feature. 


\section{Co-expression of ER, PR, and HER2}

Aside from analyzing each hormone receptor status independently, the co-expression of hormone receptors was also considered (Table 4a, 4b, 4c). Specifically, out of 54 HER2-postive cases, 70.4\% was found to have concurrent expression of both HER2 and ER, whereas $83.6 \%$ of cases showed co-expression of HER2 and PR with statistical significance (Table $4 a$ \& Table $4 b$ ). Finally, in 45 ERpositive cases, $95.6 \%$ was found to have a significant level of both ER and PR expression (Table 4c). Such findings regarding the coexpression of ER and PR is concordant with the literature, as estrogen has been shown to regulate PR expression and this may explain how prolonged use of progestin therapy confers resistance $[13,18]$.

In terms of HER2 co-expression, however, A Mariani, TJ Sebo, JA Katzmann, DL Riehle, SC Dowdy, GL Keeney, TG Lesnick and KC Podratz [19] noted an inverse correlation between HER2 and PR status, suggesting HER2 overexpression may result in the downregulation of $\mathrm{PR}$, thereby giving rise to a hormone-independent growth mechanism that is highly characteristic of type II EC. Similar to J Backe, AM Gassel, S Krebs, T Muller and H Caffier [36] and D Niederacher, HX An, YJ Cho, P Hantschmann, HG Bender and MW Beckmann [37], we were unable to replicate this finding, as only $16.4 \%$ of HER2-positive cases showed negative PR expression compared to $83.6 \%$ of cases that were positive for both HER2 and PR (Table 4b). Alternatively, EA Samsonova, NA Maksimova, AF Urmancheeva and KM Pozharisskii [38] found no significant correlation between HER2 expression and the expression of ER and PR. Interestingly, our data suggests all three receptors are co-expressed and that ER, PR, and HER2 may therefore exert a synergistic effect in the course of EC pathogenesis and progression. The mechanism of cooperative action, however, awaits further investigation.

Among our cohort of Chinese women, we found the overall positive expression rates of ER, PR, and HER2 to be $59.8 \%, 75.0 \%$, and $71.1 \%$, respectively (Table 1). When compared to a similar Chinese cohort, there were varied differences in receptor status, further supporting the notion that there are various subtypes of EC that do not fit in the traditionally dualistic classification of EC lesions. Furthermore, HER2 expression was higher in type I lesions and the positive rate was comparable to those found for ER and PR expression (Table 2).

Independent receptor status was also associated with some, but not all clinicopathologic features (Table 2). In particular, ER expression was associated with FIGO staging, while PR expression correlated with histologic type with statistical significance. This suggests ER receptor status may be a better indicator of FIGO staging while PR expression is more correlated to histologic type. HER2 receptor status, known for its association with the more aggressive phenotype of EC, surprisingly demonstrated low expression in UPSC ( $0 \%$ ) and in all type II lesions (25\%) compared to the high expression found in EEC (71.2\%) (Table 3). Such disparity against the literature may be attributable to the small number of UPSC cases. A larger sample size and continued investigation is necessary to better elucidate the association between HER2 receptor status and UPSC. The present study further suggested that all three hormone receptors are co-expressed and most likely exert a cooperative effect (Table 4a, 4b, 4c).

\section{Conclusions}

Our data further underscores the need to view EC as a dynamic and heterogeneous disease. When selecting treatment, it is also of vital importance for clinicians to consider the full breadth of clinicopathologic features while analyzing each patient on an individual basis, as hormone receptor status may vary for different clinicopathologic features. Further investigation focusing not only on associations between various receptor statuses and types of EC, but also into the mechanistic role that various receptors play in the pathogenesis of EC is further warranted to fully understand the prognostic significance of hormone receptor expression in both the progression and management of EC.

\section{List Of Abbreviations}

ER (estrogen receptor); PR (progesterone receptor); HER-2 (human epidermal growth factor receptor 2); EC (endometrial cancer); IHC (Immunohistochemistry)

\section{Declarations}

\section{Ethics approval and consent to participate}


All procedures performed in studies involving human participants were in accordance with the ethical standards of the institutional and/or national research committee and with the 1964 Helsinki declaration and its later amendments or comparable ethical standards. Ethical approval for this study was provided by Xi'an Jiaoting University.

\section{Consent for publication}

Not applicable.

\section{Availability of data and materials}

All data generated or analyzed during this study are included in this published article

\section{Competing interests}

The authors declare that they have no competing interests.

\section{Funding}

This work was supported by the Shaanxi Science and Technology Project\# 2004K13-G2 (to CW), Xian Jiaotong University Natural Science Foundation\# XJJ2003021 (to CW), and the Elaine H. Snyder Cancer Research Award (to SWF).

\section{Authors' contributions}

FCW conducted the IHC experiments, statistical analysis, data interpretation, and contributed to the manuscript preparation. DAT and MZF contributed to data interpretation and manuscript writing and revision. SWF and XL designed the study, interpreted the data and finalized the manuscript.

\section{Acknowledgements}

Not applicable.

\section{References}

1.Lortet-Tieulent J, Ferlay J, Bray F, Jemal A: International Patterns and Trends in Endometrial Cancer Incidence, 1978-2013. J NatI Cancer Inst 2018, 110(4):354-361.

2.Morice P, Leary A, Creutzberg C, Abu-Rustum N, Darai E: Endometrial cancer. The Lancet 2016, 387(10023):1094-1108.

3.Waqar S, Khan SA, Sarfraz T, Waqar S: Expression of Estrogen Receptors (ER), Progesterone Receptors (PR) and HER-2/neu receptors in Endometrial Carcinoma and their associations with histological types, grades and stages of the tumor. Pak J Med Sci 2018, 34(2):266-271.

4.Talhouk A, McAlpine JN: New classification of endometrial cancers: the development and potential applications of genomic-based classification in research and clinical care. Gynecol Oncol Res Pract 2016, 3:14.

5.Society AC: Facts \& Figures 2019. In. Atlanta, GA: American Cancer Society 2019.

6.Jiang X, Tang H, Chen T: Epidemiology of gynecologic cancers in China. J Gynecol Oncol 2018, 29(1):e7.

7.Henley SJ: Uterine Cancer Incidence and Mortality-United States, 1999-2016. MMWR Morbidity and Mortality Weekly Report 2018. 
8. Howlader N, Noone A, Krapcho M, Miller D, Brest A, Yu M, Ruhl J, Tatalovich Z, Mariotto A, Lewis D et al: SEER Cancer Statistics Review, 1975-2016. In. Bethesda, MD: National Cancer Institute 2019.

9.Chen W, Zheng R, Baade PD, Zhang S, Zeng H, Bray F, Jemal A, Yu XQ, He J: Cancer statistics in China, 2015. CA Cancer J Clin 2016, 66(2):115-132.

10.Tangjitgamol S, Anderson BO, See HT, Lertbutsayanukul C, Sirisabya N, Manchana T, Ilancheran A, Lee KM, Lim SE, Chia Y-N et al: Management of endometrial cancer in Asia: consensus statement from the Asian Oncology Summit 2009. Lancet Oncology; London 2009. 10(11):1119-1127.

11.Bokhman JV: Two pathogenetic types of endometrial carcinoma. Gynecol Oncol 1983, 15(1):10-17.

12.Murali R, Soslow RA, Weigelt B: Classification of endometrial carcinoma: more than two types. Lancet Oncol 2014, 15(7):e268278.

13.Zhang Y, Zhao D, Gong C, Zhang F, He J, Zhang W, Zhao Y, Sun J: Prognostic role of hormone receptors in endometrial cancer: a systematic review and meta-analysis. World Journal of Surgical Oncology 2015, 13(1).

14.Buza N, Roque DM, Santin AD: HER2/neu in Endometrial Cancer: A Promising Therapeutic Target With Diagnostic Challenges. Arch Pathol Lab Med 2014, 138(3):343-350.

15.Lee YC, Lheureux S, Oza AM: Treatment strategies for endometrial cancer: current practice and perspective. Curr Opin Obstet Gynecol 2017, 29(1):47-58.

16.Kokka F, Brockbank E, Oram D, Gallagher C, Bryant A: Hormonal therapy in advanced or recurrent endometrial cancer. Cochrane Database Syst Rev 2010(12):CD007926.

17.Shen F, Gao Y, Ding J, Chen Q: Is the positivity of estrogen receptor or progesterone receptor different between type 1 and type 2 endometrial cancer? Oncotarget 2017, 8(1):506-511.

18.Yang S, Thiel KW, Leslie KK: Progesterone: the ultimate endometrial tumor suppressor. Trends Endocrinol Metab 2011, 22(4):145-152.

19.Mariani A, Sebo TJ, Katzmann JA, Riehle DL, Dowdy SC, Keeney GL, Lesnick TG, Podratz KC: HER-2/neu overexpression and hormone dependency in endometrial cancer: analysis of cohort and review of literature. Anticancer Res 2005, 25(4):2921-2927.

20.Leslie KK, Thiel KW, Reyes HD, Yang S, Zhang Y, Carlson MJ, Kumar NS, Dai DD: The estrogen receptor joins other cancer biomarkers as a predictor of outcome. Obstet Gynecol Int 2013, 2013:479541.

21.Dumesic DA, Lobo RA: Cancer risk and PCOS. Steroids 2013, 78(8):782-785.

22.J. Diver E, Foster R, Rueda BR, Growdon WB: The Therapeutic Challenge of Targeting HER2 in Endometrial Cancer. The Oncologist 2015, 20(9):1058-1068.

23.Tangjitgamol S, Manusirivithaya S, Srijaipracharoen S, Khunnarong J, Tanvanich S, Katanyu K, Thavaramara T, Pataradool K: Endometrial cancer in Thai women: clinico-pathological presentation and survival. Asian Pac J Cancer Prev 2010, 11(5):1267-1272.

24.Carlson M, Thiel K, Leslie K: Past, present, and future of hormonal therapy in recurrent endometrial cancer. International Journal of Women's Health 2014:429.

25.Lee WL, Yen MS, Chao KC, Yuan CC, Ng HT, Chao HT, Lee FK, Wang PH: Hormone therapy for patients with advanced or recurrent endometrial cancer. J Chin Med Assoc 2014, 77(5):221-226.

26.Jeon Y-T, Park I-A, Kim Y-B, Kim JW, Park N-H, Kang S-B, Lee H-P, Song Y-S: Steroid receptor expressions in endometrial cancer: Clinical significance and epidemiological implication. Cancer Letters 2006, 239(2):198-204. 
27.Kleine W, Maier T, Geyer H, Pfleiderer A: Estrogen and progesterone receptors in endometrial cancer and their prognostic relevance. Gynecol Oncol 1990, 38(1):59-65.

28.Tomica D, Ramic S, Danolic D, Susnjar L, Peric-Balja M, Puljiz M: Impact of oestrogen and progesterone receptor expression in the cancer cells and myometrium on survival of patients with endometrial cancer. J Obstet Gynaecol 2018, 38(1):96-102.

29.Kreizman-Shefer H, Pricop J, Goldman S, Elmalah I, Shalev E: Distribution of estrogen and progesterone receptors isoforms in endometrial cancer. Diagnostic Pathology 2014, 9(1):77.

30.Bendifallah S, Canlorbe G, Collinet P, Arsene E, Huguet F, Coutant C, Hudry D, Graesslin O, Raimond E, Touboul C et al: Just how accurate are the major risk stratification systems for early-stage endometrial cancer? Br J Cancer 2015, 112(5):793-801.

31.Maniketh I, Ravikumar G, Crasta JA, Prabhu R, Vallikad E: Estrogen and Progesterone Receptor Expression in Endometrioid Endometrial Carcinomas: A Clinicopathological Study Middle East Journal of Cancer 2014, 5(2):67-73.

32.Wang D-P, Konishi I, Koshiyama M, Mandai M, Nabu Y, Ishikawa Y, Mori T, Fuji S: Expression of c-erbb-2 protein and epidermal growth factor receptor in endometrial carcinomas correlation with clinicopathologic and sex steroid receptor status. Cancer 1993. 72(9):2628-2637.

33.Xu M, Schwartz P, Rutherford T, Azodi M, Santin A, Silasi D, Martel M, Hui P: HER-2/neu receptor gene status in endometrial carcinomas: a tissue microarray study. Histopathology 2010, 56(2):269-273.

34.Santin AD, Bellone S, Gokden M, Palmieri M, Dunn D, Agha J, Roman JJ, Hutchins L, Pecorelli S, O'Brien T et al: Overexpression of HER-2/neu in uterine serous papillary cancer. Clin Cancer Res 2002, 8(5):1271-1279.

35.Togami S, Sasajima Y, Oi T, Ishikawa M, Onda T, Ikeda S, Kato T, Tsuda H, Kasamatsu T: Clinicopathological and prognostic impact of human epidermal growth factor receptor type 2 (HER2) and hormone receptor expression in uterine papillary serous carcinoma. Cancer Sci 2012, 103(5):926-932.

36.Backe J, Gassel AM, Krebs S, Muller T, Caffier H: Immunohistochemically detected HER-2/neu-expression and prognosis in endometrial carcinoma. Arch Gynecol Obstet 1997, 259(4):189-195.

37.Niederacher D, An HX, Cho YJ, Hantschmann P, Bender HG, Beckmann MW: Mutations and amplification of oncogenes in endometrial cancer. Oncology 1999, 56(1):59-65.

38.Samsonova EA, Maksimova NA, Urmancheeva AF, Pozharisskii KM: [Expression of estrogen and progesterone receptors and oncoprotein HER-2 as a marker for clinical course and outcome in endometrioid adenocarcinoma of the uterine body (immunohistologic study)]. Vopr Onkol 2004, 50(2):196-201.

\section{Tables}

Table 1. Overall Expression of ER, PR, and HER2

\begin{tabular}{llllll}
\hline \multicolumn{2}{c}{ ER Expression n=82 } & \multicolumn{2}{c}{ PR Expression n=80 } & HER2 Expression n=76 \\
\hline Positive (\%) & Negative (\%) & Positive (\%) & Negative (\%) & Positive (\%) & Negative (\%) \\
& & & & & \\
\hline $49(59.8)$ & $33(40.2)$ & $60(75.0)$ & $20(25.0)$ & $54(71.1)$ & $22(28.9)$ \\
\hline
\end{tabular}

Table 2. Association of ER, PR, and HER2 Expression with Clinicopathologic Features 


\begin{tabular}{|c|c|c|c|c|c|c|c|c|c|c|c|c|}
\hline \multirow{2}{*}{$\begin{array}{l}\text { Clinicopathologic } \\
\text { Feature }\end{array}$} & \multicolumn{4}{|c|}{ ER Expression } & \multicolumn{4}{|c|}{ PR Expression } & \multicolumn{4}{|c|}{ HER2 Expression } \\
\hline & Cases & $\begin{array}{l}\text { Positive } \\
\text { (\%) }\end{array}$ & $\begin{array}{l}\text { Negative } \\
\text { (\%) }\end{array}$ & $\begin{array}{c}\mathrm{p}- \\
\text { value }\end{array}$ & Cases & $\begin{array}{l}\text { Positive } \\
\text { (\%) }\end{array}$ & $\begin{array}{l}\text { Negative } \\
\text { (\%) }\end{array}$ & $\begin{array}{c}\mathrm{p}- \\
\text { value }\end{array}$ & Cases & $\begin{array}{l}\text { Positive } \\
\text { (\%) }\end{array}$ & $\begin{array}{l}\text { Negative } \\
\text { (\%) }\end{array}$ & $\begin{array}{c}\text { p- } \\
\text { value }\end{array}$ \\
\hline $\begin{array}{c}\text { Bokhman } \\
\text { Subtype }\end{array}$ & 80 & & & 0.628 & 80 & & & $0.046^{*}$ & 72 & & & 0.202 \\
\hline Type I & 76 & $\begin{array}{c}48 \\
(63.2)\end{array}$ & $\begin{array}{c}28 \\
(36.8)\end{array}$ & & 76 & $\begin{array}{c}59 \\
(77.6)\end{array}$ & $\begin{array}{c}17 \\
(22.4)\end{array}$ & & 68 & $\begin{array}{c}49 \\
(72.1)\end{array}$ & $\begin{array}{c}19 \\
(27.9)\end{array}$ & \\
\hline Type II & 4 & $2(50)$ & $2(50)$ & & 4 & $1(25.0)$ & $3(75.0)$ & & 4 & $1(25.0)$ & $3(75.0)$ & \\
\hline FIGO Staging & 82 & & & $0.047^{*}$ & 80 & & & 0.094 & 75 & & & 0.913 \\
\hline I & 55 & $\begin{array}{c}38 \\
(69.1)\end{array}$ & $\begin{array}{c}17 \\
(30.9)\end{array}$ & $0.022 *$ & 53 & $\begin{array}{c}43 \\
(81.1)\end{array}$ & $\begin{array}{c}10 \\
(18.9)\end{array}$ & $0.057^{*}$ & 48 & $\begin{array}{c}34 \\
(70.8)\end{array}$ & $\begin{array}{c}14 \\
(29.2)\end{array}$ & 0.912 \\
\hline II & 18 & 7 (38.9) & $\begin{array}{c}11 \\
(61.1)\end{array}$ & 0.254 & 18 & $\begin{array}{c}10 \\
(55.6)\end{array}$ & $8(44.4)$ & 1 & 18 & $\begin{array}{c}13 \\
(72.2)\end{array}$ & $5(27.8)$ & 1 \\
\hline III \& IV & 9 & $4(44.4)$ & $5(55.6)$ & 1 & 9 & $7(77.8)$ & $2(22.2)$ & 0.406 & 9 & $7(77.8)$ & 2 & 1 \\
\hline Histologic Grade & 80 & & & 0.097 & 78 & & & 0.527 & 74 & & & 0.783 \\
\hline G1 & 31 & $\begin{array}{c}23 \\
(74.2)\end{array}$ & $8(25.8)$ & $0.031 *$ & 29 & $\begin{array}{c}24 \\
(82.8)\end{array}$ & $5(17.2)$ & 0.265 & 27 & $\begin{array}{c}19 \\
(70.4)\end{array}$ & $8(29.6)$ & 0.591 \\
\hline $\mathrm{G} 2$ & 39 & $\begin{array}{c}19 \\
(48.7)\end{array}$ & $\begin{array}{c}20 \\
(51.3)\end{array}$ & 0.441 & 38 & $\begin{array}{c}27 \\
(71.1)\end{array}$ & $\begin{array}{c}11 \\
(28.9)\end{array}$ & 0.660 & 38 & $\begin{array}{c}29 \\
(76.3)\end{array}$ & $9(23.7)$ & 1 \\
\hline G3 & 10 & $6(60.0)$ & $4(40.0)$ & 0.725 & 11 & $8(72.7)$ & $3(27.3)$ & 1 & 9 & $6(66.7)$ & $3(33.3)$ & 0.674 \\
\hline $\begin{array}{l}\text { Invasion of } \\
\text { Myometrium }\end{array}$ & 82 & & & 0.766 & 80 & & & 0.162 & 73 & & & 0.916 \\
\hline Invasion $>50 \%$ & 16 & $9(56.3)$ & 7 (53.7) & 0.848 & 16 & $\begin{array}{c}11 \\
(68.8)\end{array}$ & $5(31.2)$ & 1 & 12 & $9(75.0)$ & $3(25.0)$ & 1 \\
\hline Invasion $\leq 50 \%$ & 56 & $\begin{array}{c}33 \\
(58.9)\end{array}$ & $\begin{array}{c}23 \\
(41.1)\end{array}$ & 0.683 & 55 & $\begin{array}{c}39 \\
(70.9)\end{array}$ & $\begin{array}{c}16 \\
(29.1)\end{array}$ & 0.123 & 52 & $\begin{array}{c}37 \\
(71.2)\end{array}$ & $\begin{array}{c}15 \\
(28.8)\end{array}$ & 1 \\
\hline Non-invasion & 10 & $7(70.0)$ & $3(30.0)$ & 0.728 & 9 & $9(100)$ & $0(0)$ & 0.097 & 9 & $6(66.7)$ & $3(33.3)$ & 1 \\
\hline $\begin{array}{l}\text { Invasion of } \\
\text { Cervix }\end{array}$ & 81 & & & & 80 & & & 0.083 & 73 & & & 0.766 \\
\hline Invasion & 19 & 7 (36.8) & $\begin{array}{c}12 \\
(63.2)\end{array}$ & $0.016^{*}$ & 19 & $\begin{array}{c}11 \\
(57.9)\end{array}$ & $8(42.1)$ & & 16 & $\begin{array}{c}11 \\
(68.8)\end{array}$ & 5 & \\
\hline Non-invasion & 62 & $\begin{array}{c}42 \\
(67.7)\end{array}$ & $\begin{array}{c}20 \\
(32.3)\end{array}$ & & 61 & $\begin{array}{c}48 \\
(78.7)\end{array}$ & $\begin{array}{c}13 \\
(21.3)\end{array}$ & & 57 & $\begin{array}{c}41 \\
(71.9)\end{array}$ & 16 & \\
\hline
\end{tabular}

Table 3. Distribution of HER2 Expression in Histopathological Subtypes of Endometrial Cancer

\begin{tabular}{cc|cccc}
\hline & & \multicolumn{5}{|c}{ Histopathological Subtype } \\
\hline $\begin{array}{c}\text { Degree of HER2 Expression } \\
\text { (IHC Score) }\end{array}$ & $\begin{array}{c}\text { Case } \\
\mathbf{n}=72(\%)\end{array}$ & $\begin{array}{c}\text { EEC* } \\
\text { UPSC }\end{array}$ & CCC & SC \\
\hline 0 & $22(30.6)$ & $19(27.9)$ & $1(100)$ & $1(50)$ & $1(100)$ \\
$1+$ & $39(54.2)$ & $38(55.9)$ & & $1(50)$ & \\
$2+$ & $9(12.5)$ & $9(13.2)$ & & & \\
$3+$ & $2(2.8)$ & $2(2.9)$ & & & \\
\hline 3 & 69.4 & 72.1 & 0 & 50 & 0 \\
\hline
\end{tabular}

Table 4a. Co-expression of HER2 and ER 


\begin{tabular}{|c|c|c|c|c|c|c|c|}
\hline & \multirow[b]{2}{*}{$\begin{array}{c}\text { HER2 } \\
\text { Expression } \\
(-)\end{array}$} & \multicolumn{3}{|c|}{ ER ExpressionPositive Rate (\%) } & $\begin{array}{c}\mathrm{X}^{2} \\
7.566 \\
\end{array}$ & \multirow{2}{*}{$\begin{array}{c}\text { OR }(95 \% \mathrm{CI}) \\
4.156 \\
\\
(1.459-11.839)\end{array}$} & \multirow{2}{*}{$\begin{array}{c}\text { P-value } \\
0.006^{*}\end{array}$} \\
\hline Cases & & $\mid \begin{array}{l}(-) \\
14\end{array}$ & $(+)$ & 36.4 & 7.566 & & \\
\hline 54 & $(+)$ & 16 & 38 & 70.4 & & & \\
\hline
\end{tabular}

Table 4b. Co-expression of HER2 and PR

\begin{tabular}{|c|c|c|c|c|c|c|c|}
\hline & & PR E & ressi & ive Rate (\%) & $\mathrm{X}^{2}$ & OR $(95 \% \mathrm{CI})$ & P-value \\
\hline Cases & $\begin{array}{c}\text { HER2 } \\
\text { Expression } \\
(-)\end{array}$ & $\begin{array}{l}(-) \\
10\end{array}$ & $\begin{array}{l}(+) \\
11\end{array}$ & 52.4 & 7.918 & $\begin{array}{c}4.646 \\
(1.523-14.173)\end{array}$ & $0.005^{*}$ \\
\hline 55 & $(+)$ & 9 & 46 & 83.6 & & & \\
\hline
\end{tabular}

Table 4c. Co-expression of ER and PR

\begin{tabular}{|c|c|c|c|c|c|c|c|}
\hline \multirow[b]{2}{*}{$\begin{array}{c}\text { Cases } \\
(n=77)\end{array}$} & \multirow[b]{2}{*}{\begin{tabular}{|c|} 
ER \\
Expression \\
$(-)$
\end{tabular}} & \multicolumn{3}{|c|}{ PR ExpressionPositive Rate (\%) } & \multirow{2}{*}{$\begin{array}{c}\mathrm{X}^{2} \\
26.104\end{array}$} & \multirow{2}{*}{$\begin{array}{c}\text { OR }(95 \% \mathrm{CI}) \\
27.643\end{array}$} & \multirow{2}{*}{$\frac{\text { P-value }}{}$} \\
\hline & & $\begin{array}{l}(-) \\
18\end{array}$ & $(+)$ & 43.8 & & & \\
\hline 45 & $(+)$ & 2 & 43 & 95.6 & & & \\
\hline
\end{tabular}

\section{Figures}




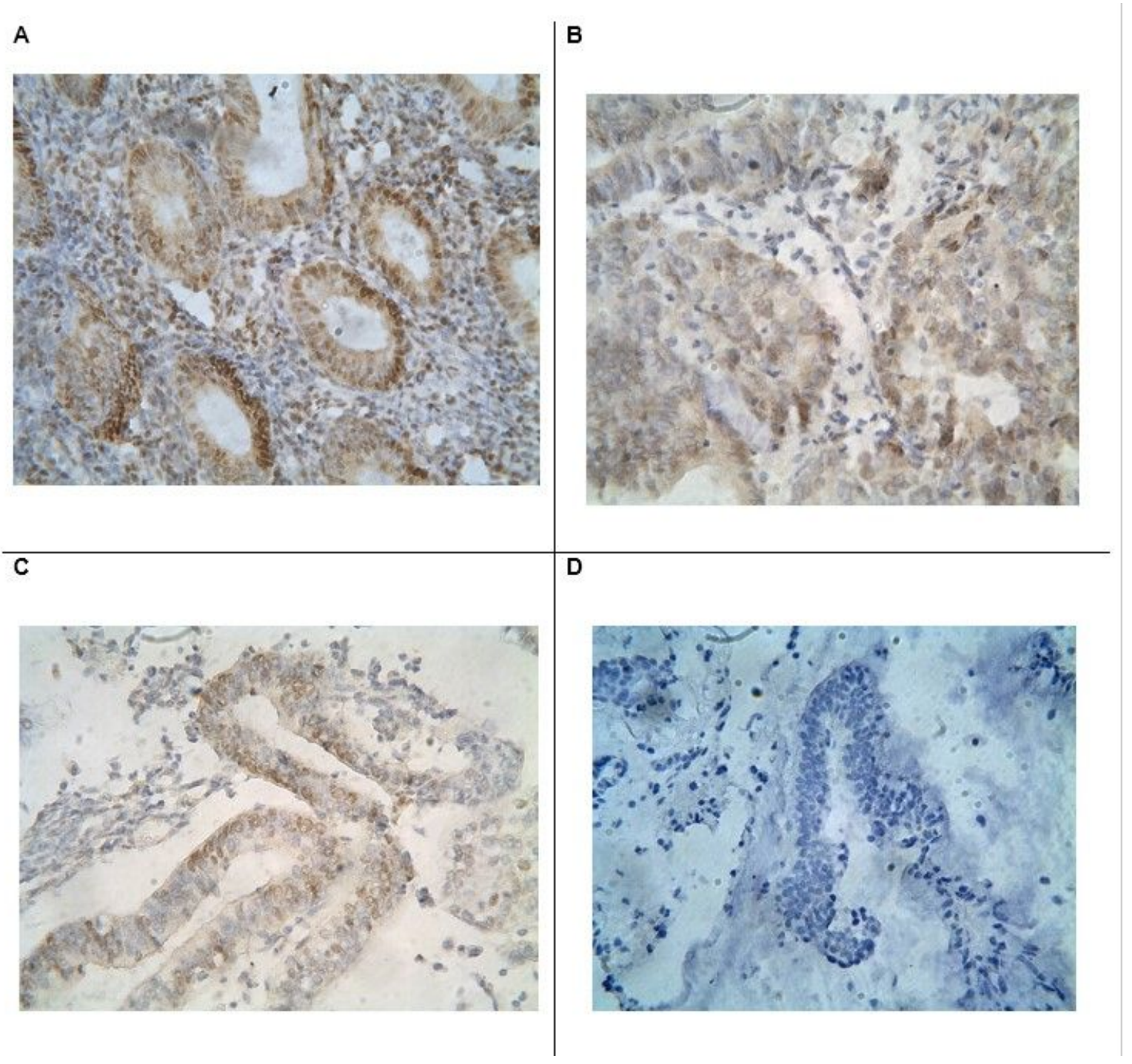

\section{Figure 1}

ER protein expression in EC tissues by IHC (40x). Representative EC FFPE tissues with IHC staining of ER. IHC shows nuclear stain positivity for ER expression in the cell nucleus. IHC results are shown at 40x magnification. 


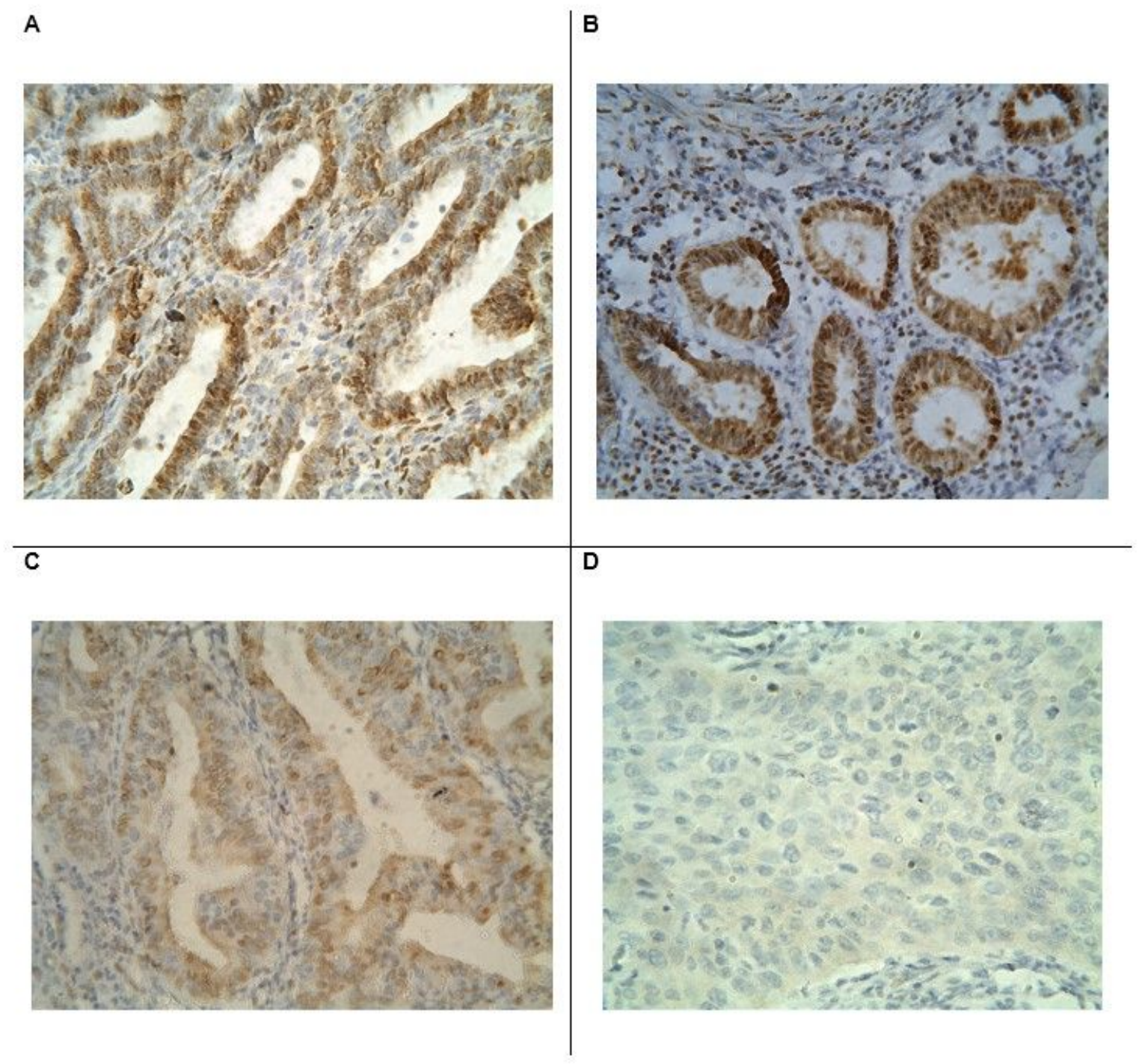

Figure 2

PR protein expression in EC tissues by IHC (40x). Representative EC FFPE tissues with IHC staining of PR. IHC show nuclear stain positivity for PR expression in the cell nucleus. IHC results are shown at $40 x$ magnification. 


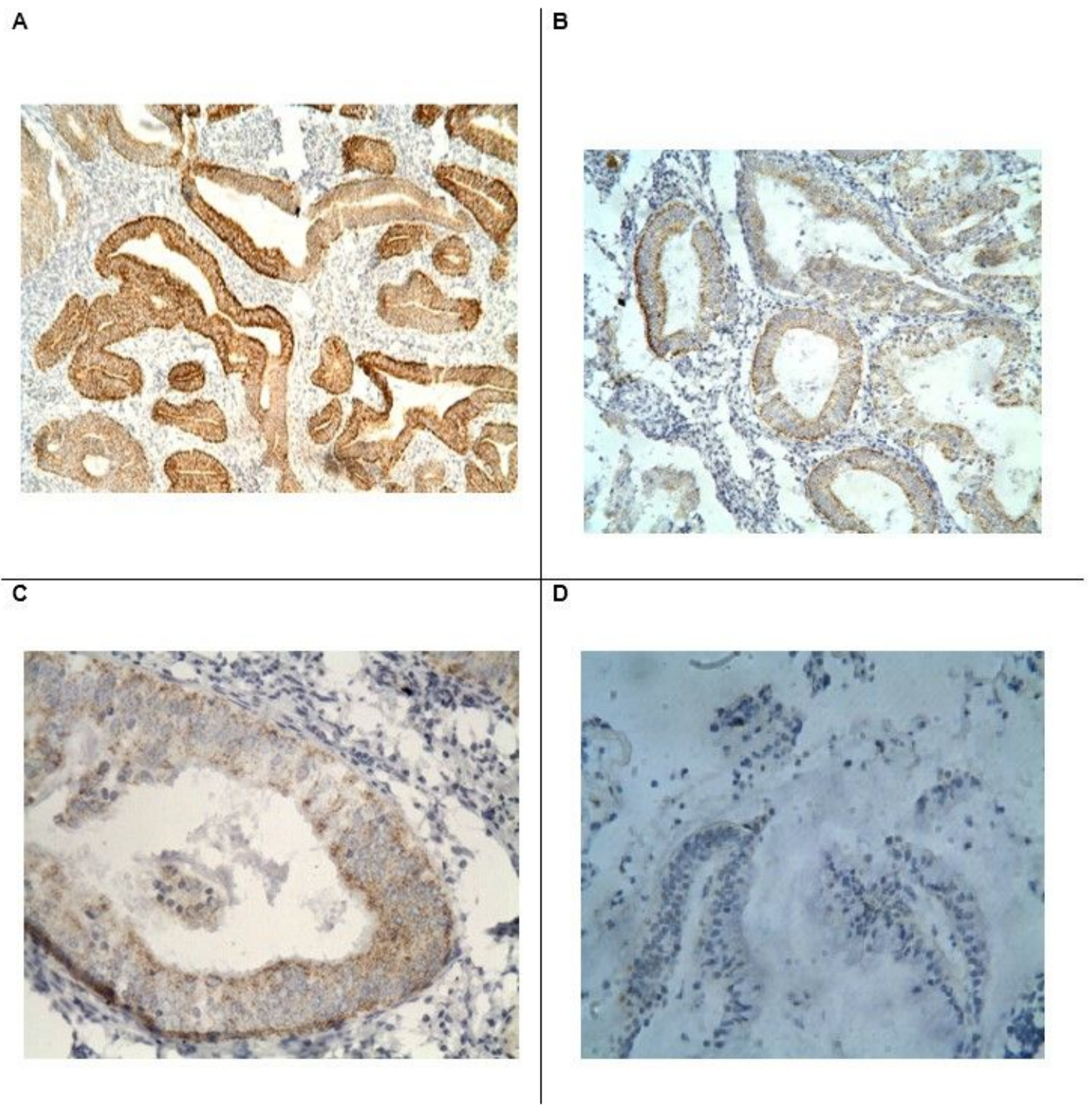

Figure 3

HER2 protein expression in EC tissues by IHC (A\&B 20x; C\&D 40x). Representative EC FFPE tissues with IHC staining of HER2. HER2 expression was mainly found expressed in the cell membrane and cell cytoplasm. (A\&B) IHC results are shown at 20x magnification; (C\&D) IHC results are shown at $40 x$ magnification. 